\title{
ASSESSING COMPLIANCE TO COVID-19 PROTOCOLS AMONG LICENSED HOSPITALITY PROVIDERS IN THE HO MUNICIPALITY OF THE VOLTA REGION OF GHANA
}

\section{Michael Dabi ${ }^{1}$, Eric Tackie Tawiah Ankrah ${ }^{2}$}

1. Evangelical Presbyterian University College, School of Agriculture and Environmental Sciences, Department of Environmental Science, P.O. Box HP 678, Ho - Ghana.

Email: michael.dabi@epuc.edu.gh (Corresponding author).

2. Ghana Tourism Authority, Volta Regional Office, $3^{\text {rd }}$ Floor, SIC Building, P. O. Box HP 568, Ho - Ghana.

Email: ettankrah@visitghana.com

\begin{abstract}
The present study assessed compliance with COVID-19 prevention protocols in the hospitality industry in the Ho Municipality of the Volta Region of Ghana. The study employed secondary data gathered in February 2021 from a 3-day field exercise undertaken by the Ghana Tourism Authority on the compliance of the Safety Protocols on the COVID-19 pandemic by operators in the hospitality industry. A total of sixty units (20 hotels, 20 local restaurants, and 20 Drinking Bars) were selected using a mixture of probability and non-probability sampling techniques such as stratified, purposive, and simple random sampling. The resulting data gathered using structured questionnaire and observations were coded and entered into SPSS for analysis. Results showed that all sectors and units were adhering to the proposed safety protocols to an appreciable extent. The study made recommendations in line with WHO standard protocols for preventing the spread of the virus, and regular monitoring of hospitality facilities in the municipality and beyond to ensure compliance.
\end{abstract}

\section{INTRODUCTION}

Recent epidemiological literature is replete with studies on COVID-19 (e.g., Lv et al., 2020; Steffens, 2020; Wu et al., 2020; Livingston \& Bucher, 2020). Most of these studies and publications have looked at diagnosis and prognosis (e.g., Pourbagheri-Sigaroodi et al., 2020; Zhao, 2020; Ong et al., 2020; Bashash et al., 2020). Others have concentrated on vaccine development (e.g., Le et al., 2020; Graham, 2020; Corey et al., 2020). Some still have been concerned with recommendations for controlling the virus's spread and personal caution (e.g., Walke, 2020; Adhikari et al., 2020; Guner et al., 2020; Xiao \& Torok, 2020). However, there remains a paucity of data on compliance with safety protocols to curb the virus's spread.

COVID-19 (formerly referred to as '2019 novel coronavirus' or '2019-nCoV') is a respiratory disease caused by a nouveau strain of coronavirus. The 'CO' in the abbreviation stands for corona, the 
'VI' for virus, and the 'D' for disease. So, the acronym means the coronavirus disease discovered in the year 2019. The COVID-19 virus is a new virus linked to the same family of viruses as Severe Acute Respiratory Syndrome (SARS) and some types of common cold (Bender, 2020). The World Health Organisation (WHO) records that most people who fall sick with COVID-19 will experience mild to moderate symptoms and recover without special treatment. Alhazzani (2020) reports that the clinical exhibition of infection may range from asymptomatic - that is, showing no symptoms, to very severe pneumonia with acute respiratory distress syndrome, septic shock and multiorgan failure, which may eventually result in death.

Available evidence from the World Health Organisation (WHO, 2020) shows that the virus that causes COVID-19 transmits through droplets generated when an infected person coughs, sneezes, or exhales. Further evidence (e.g., from Jayaweera, 2020; Ueki, 2020; and In't Veen et al., 2020) show that these droplets are too heavy to hang in the air and quickly fall on floors or surfaces where they may last from minutes to hours, depending on the surface's nature. Proximity to an infected person or touching a contaminated surface and then your eyes, nose or mouth can expose a healthy person to infection (Wilson et al., 2020; Sommerstein et al., 2020)

The coronavirus disease 2019 (COVID-19) outbreak, which originated in Wuhan, China, in December, 2019, was declared a Public Health Emergency of International Concern by the WHO in January 2020, and a pandemic in March 2020 (WHO, 2020).

According to the WHO, as at the ninth week of 2021, 118 million cases of COVID-19 have been reported with 2.62 million deaths globally. Apart from a few island countries, cases have been reported from every country of the world (with the worst-hit countries being the United States of America—with 29.3 million confirmed cases and 530,000 deaths, and India-11.3 million cases with 158,000 deaths).

Africa has recorded 3.9 million cases; the five countries reporting most cases being South Africa (1.5 million), Morocco (486, 223), Tunisia (238, 017), Egypt $(186,503)$ and Ethiopia $(166,138)$. Ghana has recorded 86,737 cases with 81, 299 recoveries and 656 deaths (GHS, 2021).

As of March 9 2021, a total of 268, 205, 245 vaccine doses have been administered (WHO, 2021). Whilst trials have shown several COVID-19 vaccines to have high efficacy levels, like all other vaccines, COVID-19 vaccines will not be $100 \%$ effective. WHO is working to help ensure that approved vaccines are as effective as possible to significantly impact the pandemic (WHO, 2021).

COVID-19 safety protocols refer to specific protective measures that must be observed in certain situations to help stem the spread of the virus. The protocols include the imposition of lockdowns, adherence to social distancing, frequent handwashing and cleaning of surfaces, cough or sneeze etiquette, proper tissue usage or disposal, avoidance of touching the face, provision of accurate information to the general public, among others (Izzetti et al., 2020). The WHO recommended protocols for prevention of the spread of the virus so far include:

- wearing a mask to protect oneself and others

- $\quad$ staying at least 6 feet (about two arm lengths) from others who don't live with you (social distancing)

- avoiding crowds and poorly ventilated spaces

- handwashing with soap and water for at least 20 seconds, especially after being in a public place, or coughing, or sneezing

- always covering the mouth and nose with a tissue when sneezing or coughing or using the inside of the elbow 
- daily and frequent cleaning and disinfection of touched surfaces, including tables, doorknobs, light switches, countertops, handles, desks, phones, keyboards, toilets, faucets, and sinks.

The government of Ghana eased restrictions after its first partial lockdown during the pandemic, allowing public places to open, but with caution to heed strictly to the recommended COVID-19 protocols by the WHO. The study sought to ascertain compliance with these protocols by public places in the Ho Municipality.

\section{METHODOLOGY}

The study utilised secondary data from the Ghana Tourism Authority in Ho.

The data was gathered from a 3-day field exercise undertaken by the Ghana Tourism Authority on the compliance of the Safety Protocols on the COVID-19 pandemic by operators in the hospitality industry. The exercise was conducted from February 16 - 18, 2021, in the Ho Municipality of the Volta Region.

The Ho Municipality shares boundaries with Adaklu and Agotime-Ziope Districts to the South, Ho West District to the North and West and the Republic of Togo to the East. According to the 2010 Population and Housing Census, the population of the Ho Municipality was 177, 281, with about 62 percent of the population resides in urban localities.

As in the rest of the Region, the hospitality industry in the municipality is a thriving and burgeoning industry with new entrants every year. Data from the Ghana Tourism Authority indicates 48 hotels, 38 traditional restaurants (chop bars), and 66 drinking bars (pubs) are registered and licenced as at December, 2020 in the municipality.

A total of sixty (60) units (20 hotels, 20 local restaurants, and 20 Drinking Bars) were selected for the monitoring exercise. The team adopted a purposive sampling method to choose the hotels and random sampling for the Chop Bars and the Drinking Bars. This involved selecting most of the Budget category hotels and a few 1-Star rated ones from the list of licensed units in the Ho Municipality. Using structured questionnaires and observations, two teams of two officers gathered the data for the 3-day exercise.

Data were coded and entered into SPSS and Excel and further explored using simple frequencies and descriptive statistics.

\subsection{RESULTS}

The results are presented in three categorisations: compliance at Hotels, compliance at Chop Bars and compliance at Drinking Bars. 


\subsection{Compliance at Hotels}

Figure 1 shows the results on compliance at hotels in the study area.

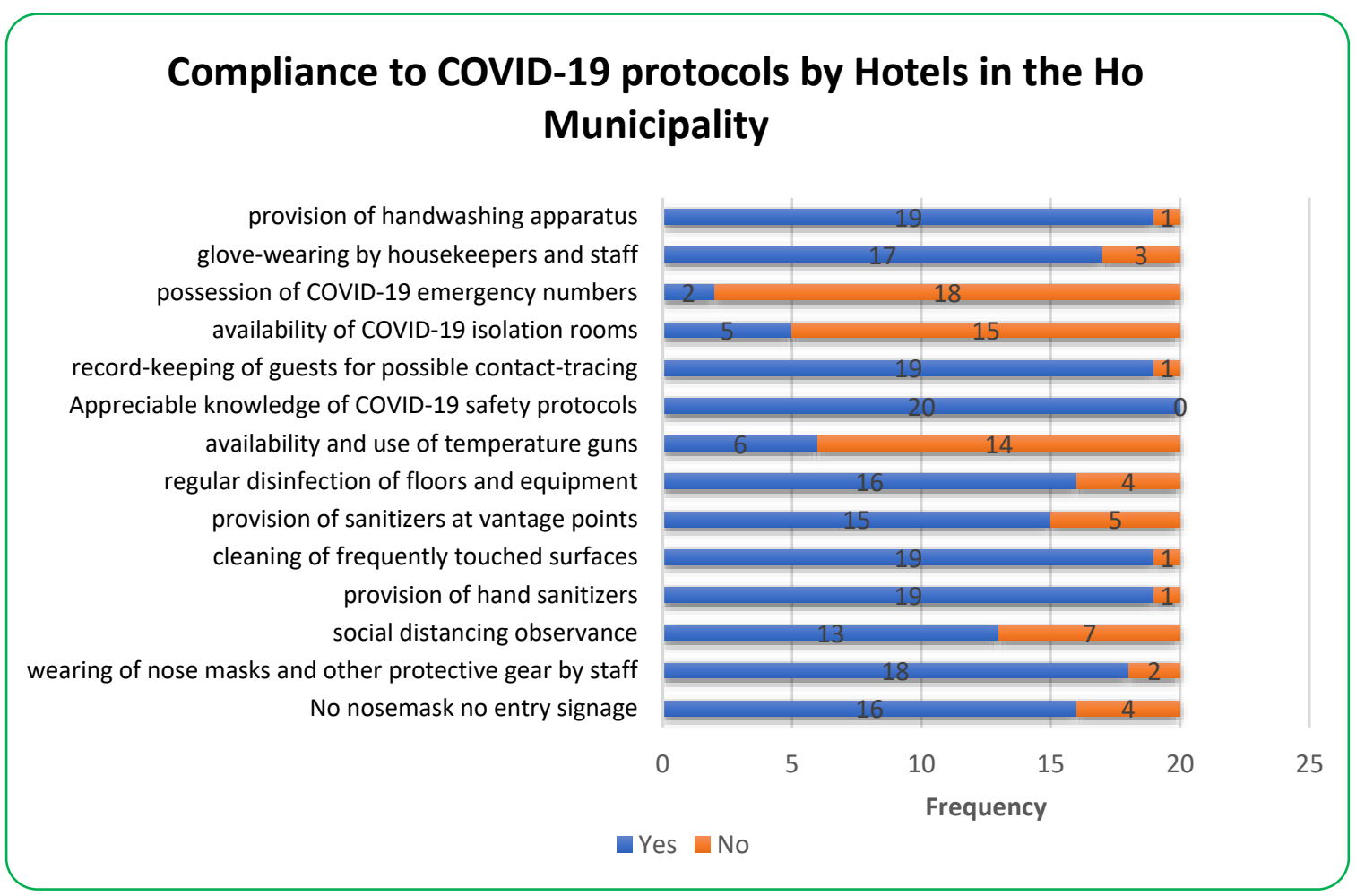

Figure 1: Stacked bar graph showing compliance to various COVID-19 protocols by Hotels in the Ho Municipality

In all, a total of 20 hotels were captured. The inspecting teams checked for the presence or absence of items listed on the questionnaire and made observations.

The protocols that recorded the highest observance during the study were: appreciable knowledge of COVID-19 protocols (100\%), availability of handwashing apparatuses at entrances or receptions (95\%), provision of hand sanitisers (95\%), cleaning of frequently touched surfaces (95\%), record-keeping of guests for possible contact-tracing (95\%), and wearing of nose masks and other protective gear by staff (90\%). Other protocols (glove-wearing by housekeepers and staff, regular disinfection of floors and equipment, and No nose-mask, no entry signage) recorded observance rates of $85 \%$ and $80 \%$.

Other protocols recorded very poor observances, e.g., possession of COVID-19 emergency numbers (10\%), availability of COVID-19 isolation rooms (25\%), and availability and use of temperature guns (30\%). 


\subsection{Compliance at Local Restaurants (Chop Bars)}

Results on compliance to protocols at the local restaurants (chop bars) are capture in the stacked bar chart in Figure 2.

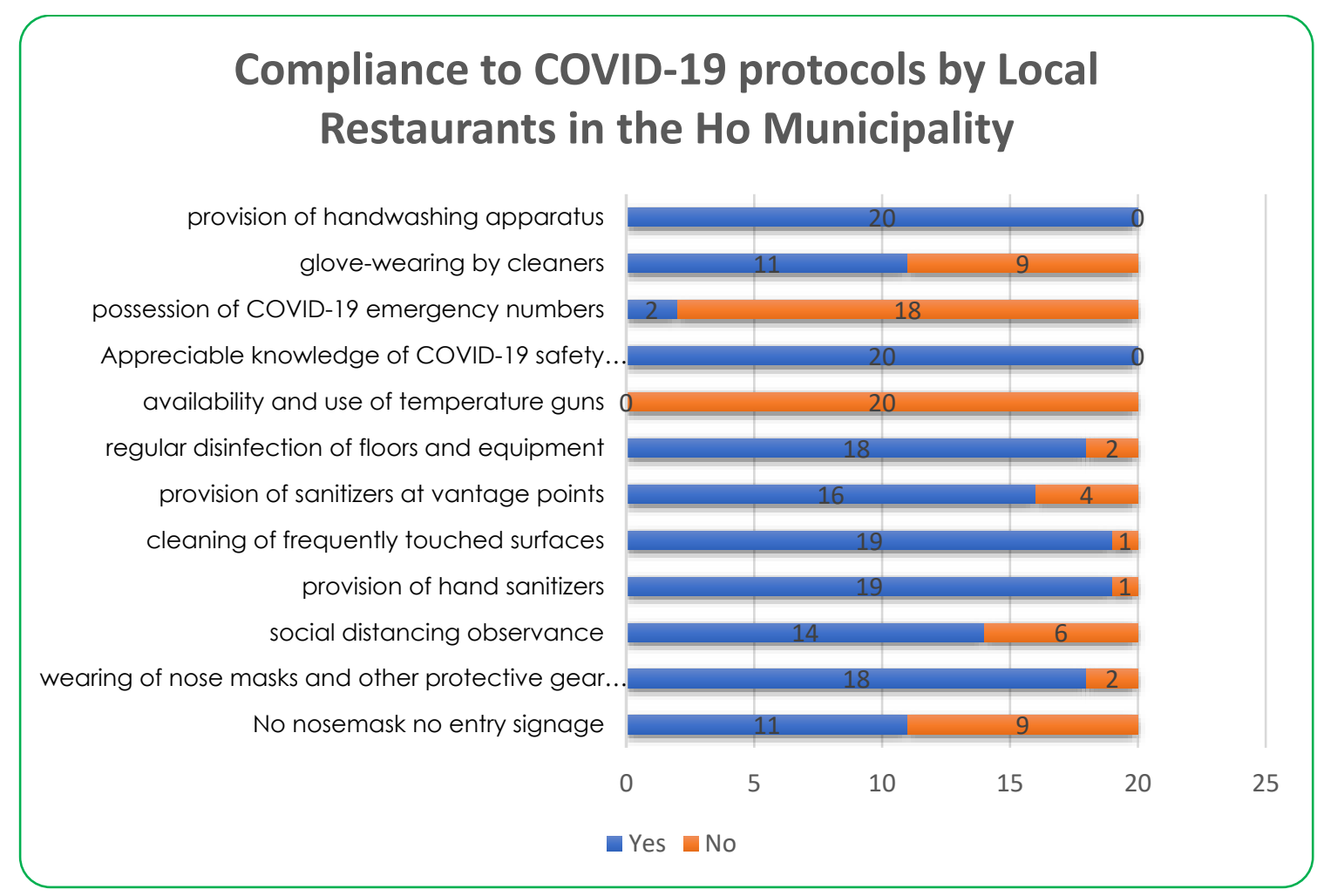

Figure 2: Stacked bar graph showing compliance to various COVID-19 protocols by Local Restaurants in the Ho Municipality

Two protocols (provision of handwashing apparatus and appreciable knowledge of COVID-19 safety protocols) had $100 \%$ compliance. Cleaning of frequently touched surfaces and provision of hand sanitisers protocols had $95 \%$ compliance. Other protocols that received relatively high observance were regular disinfection of floors and equipment (90\%) and wearing nose masks and other protective gears $(90 \%)$.

The following protocols recorded low observance rates: availability and use of temperature guns $(0 \%)$ and possession of COVID-19 emergency numbers (10\%). 


\subsection{Compliance at Drinking Bars (Pubs)}

Compliance to the protocols by the drinking bars (pubs) is shown in Figure 3.

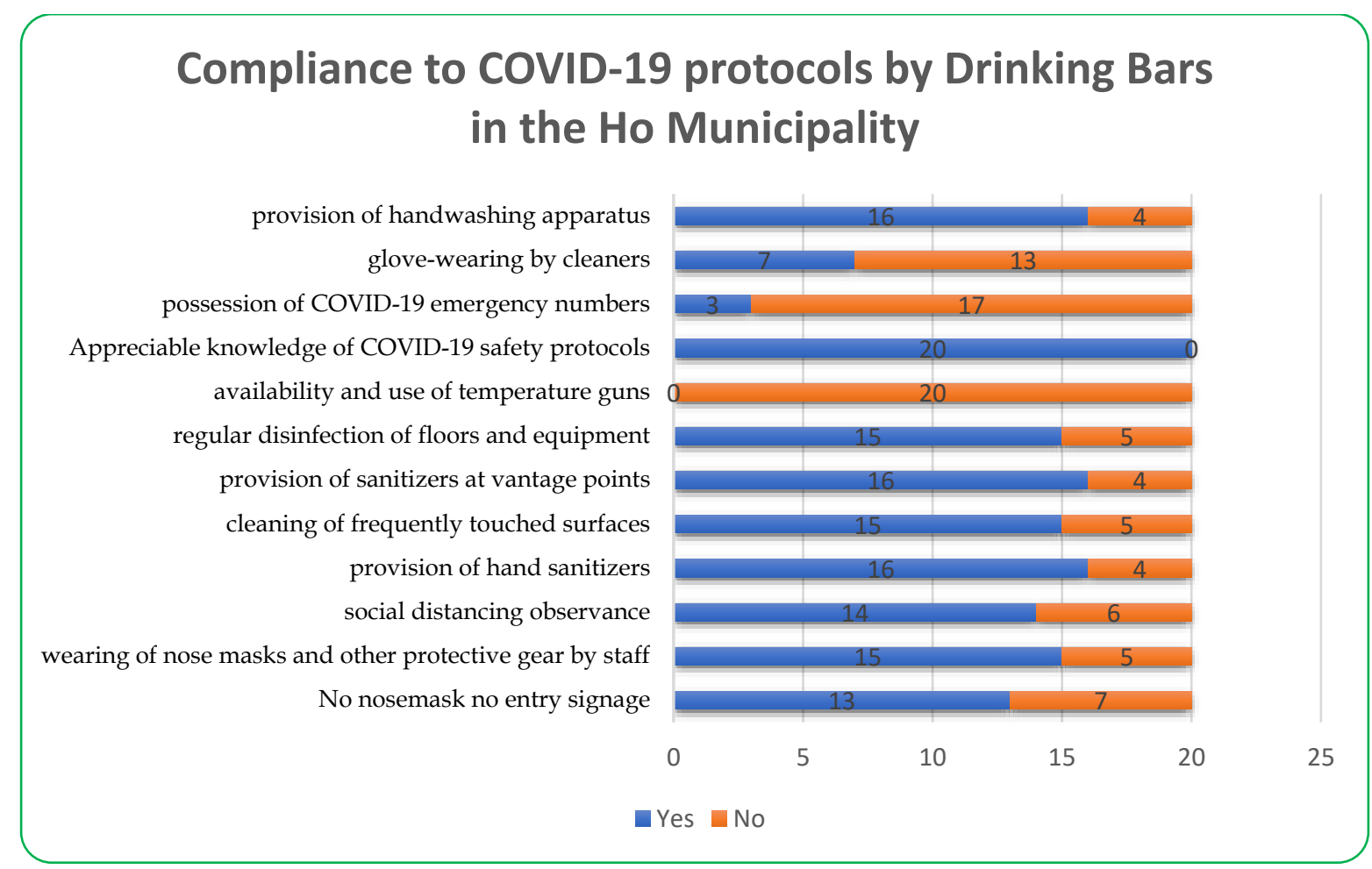

Figure 3: Stacked bar graph showing compliance to various COVID-19 protocols by Drinking bars in the Ho Municipality

All drinking bars visited had an appreciable knowledge of COVID-19 safety protocols (100\%) but no temperature guns $(0 \%)$. Other noticeable observance rates were: provision of handwashing apparatus (80\%), provision of sanitisers at vantage points (80\%), provision of hand sanitisers $(80 \%)$, regular disinfection of floors and equipment (75\%), cleaning of frequently touched surfaces (75\%), and wearing of nose masks and other protective gear by staff (75\%).

\subsection{DISCUSSION}

Overall, results showed appreciable efforts by all three sectors to observe the safety protocols of COVID-19. The key safety protocols: handwashing, wearing of nose masks, and social distancing were being complied with by all sectors and units to an appreciable extent. This may limit persons' exposure to the virus and contribute to the relatively low number of cases recorded in the Municipality.

The ECDC (2020) and CDC recommend using face masks to reduce COVID-19 transmission from potentially asymptomatic or presymptomatic people. Gunther et al. (2020) see this protocol as a primary means of source control since the vaccines are yet to provide complete immunity. With people from various places with unknown COVID-19 statuses visiting these hospitality units daily, the proper use of face masks may prove to be decisive in preventing transmission from predominantly asymptomatic persons. The appropriate use of face masks during and after wearing may reduce people coming into contact with droplets or secretions containing the virus. 
The WHO recommends social distancing as one of its effective means of decreasing the spread of the virus. Wilder-Smith \& Freedman (2020) and Gunther et al. (2020) argue that, since diseases transmitted by respiratory droplets require certain proximity of people, the social distancing of persons will reduce transmission significantly, especially in places where exposed persons have not been quarantined or isolated and lockdowns have not been enforced. The observance of social distancing at the various centres visited shows the resolve of all centres to arrest the spread of the virus.

Gunter et al. (2020) endorse regular disinfection of frequently-touched areas such as door handles with regular household disinfectant or $70 \%$ ethanol. In public places like hotels, restaurants and pubs where people gather and touch items regularly, the relatively high level of compliance to this protocol is commendable. The disinfection should be done with disposable gloves, which should be well-disposed in lined waste bins or containers.

WHO recommends alcohol-based hand sanitisers as a preventive measure of COVID-19 (Mahmood et al., 2020). These are not substitutes for handwashing except in the absence of handwashing apparatus (CDC, 2020). All sectors and units surveyed showed compliance to the provision of hand sanitisers for staff and customers. However, frequent usage of hand sanitisers has been found to enhance the chance of other viral diseases and increased antimicrobial resistance (Mahmood et al., 2020).

\section{CONCLUSIONS}

All three sectors and units surveyed in the Ho Municipality were complying with COVID-19 protocols as set out by the WHO.

\section{RECOMMENDATIONS}

Based on the findings of the study, the following are recommended:

- The Ghana Tourism Authority (GTA) should continue the monitoring and sensitisation exercises in the Ho Municipality and extend it to other Municipalities and Districts in the Region. The Authority can procure and distribute some more PPEs and other apparatus such as thermometer guns, hand sanitisers, "No Nose Mask No Entry" stickers and distribute them to operators as most had complained of bad business due to the covid-19 pandemic.

- The GTA should also help operators get the covid-19 emergency numbers displayed at their facilities and share the same on the various social media platforms for the various sectors of the hospitality and tourism industry in the Region.

- Operators, especially owners of the various facilities, must continue to provide the required PPEs and other apparatuses to ensure their staff and guests' safety.

- The GTA must ensure that the social distancing precaution is strictly adhered to by all operators.

\section{Acknowledgement}

The authors express their profound gratitude to the Ghana Tourism Authority for special permission to use their data.

\section{REFERENCES}

[1.] Adhikari, S. P., Meng, S., Wu, Y. J., Mao, Y. P., Ye, R. X., Wang, Q. Z., .. \& Zhou, H. (2020). Epidemiology, causes, clinical manifestation and diagnosis, prevention and control of coronavirus disease (COVID-19) during the early outbreak period: a scoping review. Infectious diseases of poverty, 9(1), 1-12.

[2.] Alhazzani, W., Møller, M. H., Arabi, Y. M., Loeb, M., Gong, M. N., \& Fan, E. \& Du, B. (2020). Surviving Sepsis Campaign: guidelines on the management of critically ill adults with Coronavirus Disease 2019 (COVID-19). Intensive care medicine, 1-34. 
[3.] Bashash, D., Olfatifar, M., Hadaegh, F., Aghdaei, H. A., \& Zali, M. R. (2020). COVID-19 prognosis: what we know of the significance and prognostic value of liver-related laboratory parameters in SARS-CoV-2 infection. Gastroenterology and hepatology from bed to bench, 13(4), 313.

[4.] Bender, L. (2020). Key Messages and Actions for COVID-19 Prevention and Control in Schools. UNICEF/WHO.

[5.] Corey, L., Mascola, J. R., Fauci, A. S., \& Collins, F. S. (2020). A strategic approach to COVID-19 vaccine R\&D. Science, 368(6494), 948-950.

[6.] COVID-19 situation updates worldwide, as of WEEK 8, updated March 4 2021. (2021, March 05). Retrieved March 11, 2021, from https://www.ecdc.europa.eu/en/geographicaldistribution-2019-ncov-cases

[7.] European Centers for Disease Control (ECDC) (2020). Using face masks in the community reducing COVID-19 transmission from potentially asymptomatic or presymptomatic people through the use of face masks ECDC Technical Report [online]. Website https://www.ecdc.europa.eu/en/publications-data/using-face-masks-communityreducingcovid-19-transmission [accessed 8 April 2020].

[8.] Ghana Tourism Authority, Report on COVID-19 Monitoring and Sensitisation Exercise, February, 2021, Ho, Volta Region, Ghana, Unpublished.

[9.] Graham, B. S. (2020). Rapid COVID-19 vaccine development. Science, 368(6494), 945-946.

[10.] Güner, H. R., Hasanoğlu, I., \& Aktaş, F. (2020). COVID-19: Prevention and control measures in community. Turkish Journal of medical sciences, 50(SI-1), 571-577.

[11.] In't Veen, J., de Hond, M., \& Boerstra, A. C. (2020). Virustransmissiebij covid-19 [Viral transmission in COVID-19: the role of the aerosol]. Nederlandstijdschriftvoorgeneeskunde, 164, D5399.

[12.] Izzetti, R., Nisi, M., Gabriele, M., \& Graziani, F. (2020). COVID-19 transmission in dental practice: brief review of preventive measures in Italy. Journal of dental research, 99(9), 1030-1038.

[13.] Jayaweera, M., Perera, H., Gunawardana, B., \&Manatunge, J. (2020). Transmission of COVID19 virus by droplets and aerosols: A critical review on the unresolved dichotomy. Environmental research, 188, 109819. https://doi.org/10.1016/j.envres.2020.109819

[14.] Le, T. T., Andreadakis, Z., Kumar, A., Román, R. G., Tollefsen, S., Saville, M., \& Mayhew, S. (2020). The COVID-19 vaccine development landscape. Nat Rev Drug Discov, 19(5), 305306.

[15.] Livingston, E., \& Bucher, K. (2020). Coronavirus disease 2019 (COVID-19) in Italy. Jama, 323(14), 1335-1335.

[16.] Lv, M., Luo, X., Estill, J., Liu, Y., Ren, M., Wang, J., ... \& Chen, Y. (2020). Coronavirus disease (COVID-19): a scoping review. Eurosurveillance, 25(15), 2000125.

[17.]Mahmood, A., Eqan, M., Pervez, S., Alghamdi, H. A., Tabinda, A. B., Yasar, A....\& Pugazhendhi, A. (2020). COVID-19 and frequent use of hand sanitisers; human healthand environmental hazards by exposure pathways. Science of the Total Environment, 742, 140561.

[18.]Ong, Y. E. E., Khor, Z. W., McGovern, R., Testrow, S., \& Tipton, C. (2020). Study of Outcomes and Characteristics of COVID-19 Positive Geriatric Patients in a Scottish Rehabilitation Community Hospital.

[19.] Pourbagheri-Sigaroodi, A., Bashash, D., Fateh, F., \&Abolghasemi, H. (2020). Laboratory findings in COVID-19 diagnosis and prognosis. Clinica ChimicaActa; International Journal of Clinical Chemistry, 510, 475. 
[20.] Sommerstein, R., Fux, C. A., Vuichard-Gysin, D., Abbas, M., Marschall, J., Balmelli, C., Troillet, N., Harbarth, S., Schlegel, M., Widmer, A., \& Swissnoso (2020). Risk of SARS$\mathrm{CoV}-2$ transmission by aerosols, the rational use of masks, and protection of healthcare workers from COVID-19. Antimicrobial resistance and infection control, 9(1), 100. https://doi.org/10.1186/s13756-020-00763-0

[21.] Steffens, I. (2020). A hundred days into the coronavirus disease (COVID-19) pandemic. Eurosurveillance, 25(14), 2000550.

[22.] These places have no reported covid-19 cases. (n.d.). Retrieved March 12, 2021, from https://www.usnews.com/news/best-countries/slideshows/countries-without-reported-covid19-cases?slide $=8$

[23.] Ueki, H., Furusawa, Y., Iwatsuki-Horimoto, K., Imai, M., Kabata, H., Nishimura, H., \& Kawaoka, Y. (2020). Effectiveness of Face Masks in Preventing Airborne Transmission of SARS-CoV2. mSphere, 5(5), e00637-20. https://doi.org/10.1128/mSphere.00637-20

[24.] Walke, H. T., Honein, M. A., \& Redfield, R. R. (2020). Preventing and responding to COVID-19 on college campuses. Jama, 324(17), 1727-1728.

[25.] Wilder-Smith, A., \& Freedman, D. O. (2020). Isolation, quarantine, social distancing and community containment: pivotal role for old-style public health measures in the novel coronavirus (2019-nCoV) outbreak. Journal of travel medicine, 27(2), taaa020.

[26.] Wilson, N. M., Norton, A., Young, F. P., \& Collins, D. W. (2020). Airborne transmission of severe acute respiratory syndrome coronavirus-2 to healthcare workers: a narrative review. Anaesthesia, 75(8), 1086-1095. https://doi.org/10.1111/anae.15093

[27.] Wu, F., Zhao, S., Yu, B., Chen, Y.M., Wang, W., \& Hu, Y. (2020). Complete genome characterisation of a novel coronavirus associated with severe human respiratory disease in Wuhan, China. bioRxiv. 2020;919183. http://dx.doi.org/10.1101/2020.01.24.919183

[28.] Xiao, Y., \&Torok, M. E. (2020). Taking the right measures to control COVID-19. The Lancet Infectious Diseases, 20(5), 523-524.

[29.] Zhao, J., Pang, R., Wu, J., Guo, Y., Yang, Y., Zhang, L., \& Xia, X. (2020). Clinical characteristics and outcomes of patients with COVID-19 and rheumatic disease in China' hot spot'versus in US 'hot spot': similarities and differences. Annals of the Rheumatic Diseases. 